\title{
Computational fluid dynamics analyses on the hydrodynamic entry length in internal flows
}

\section{İç akışlardaki hidrodinamik giriş uzunluğu üzerine hesaplamalı akışkanlar dinamiği analizleri}

\author{
Emre KAHRAMANOĞLU $U^{1 *}$, Savas SEZEN ${ }^{1}$, Seyfettin BAYRAKTAR ${ }^{1}$
}

1Deparment of Naval Architecture and Marine Engineering, Faculty of Naval Architecture and Maritime, Yildiz Technical University, Istanbul, Turkey.

emrek@yildiz.edu.tr, ssezen@yildiz.edu.tr, sbay@yildiz.edu.tr

Received/Geliş Tarihi: 17.10.2016, Accepted/Kabul Tarihi: 20.02.2017

* Corresponding author/Yazıșilan Yazar

doi: $10.5505 /$ pajes.2017.58908

Research Article/Araștırma Makalesi

\section{Abstract}

In the present numerical study, effects of the shape of the cross-section and their surface roughness on the pipe hydrodynamic entry length have been investigated for various Reynolds (Re) numbers. Standard $k$ - $\varepsilon$ turbulence model has been adopted to analyze the turbulent flows in circular, square and equilateral triangle cross-sectional pipes. Analyses indicate that the rough surfaces have the shorter entry lengths than that of the smooth surfaces and increasing surface roughness reduces the entry length regardless of the cross-section of the pipes. The equilateral triangle pipes have the longest while circular cross-sectional pipe has the shortest entry lengths. Re number has the significant effect on the entry length and it is seen that the higher the Re number the longer the entry length.

Keywords: Computational fluid dynamics, Internal flows, Roughness, Turbulent flows, Entrance length

\section{Introduction}

Flows through pipes and ducts are used extensively in the industrial applications such as heat exchangers, heating, ventilating and air conditioning (HVAC) applications. In fluid mechanics it is assumed that the velocity profile of the entering fluid to a pipe or duct is uniform. However, it is changed from uniform to parabolic if the flow is laminar or somewhat flatter when the flow is turbulent. The reason of this change in the velocity profile is well explained in the books on fluid mechanics [1],[2]. Because of the viscosity the fluid particles in the layer in contact with the surface of the pipe stick to the pipe wall and take its velocity. The friction between the layers of the fluid causes to slow down velocity of the adjacent layers of the fluid. Making up the reduction in the velocity, the velocity of the fluid at the mid-section of the pipe will increase to keep the mass flow rate constant. As a result, a velocity profile develops along the pipe. Velocity profile consists of two regions. These are the boundary layer region where viscous effects are dominant and the outer region where the flow is assumed inviscid. Boundary layer thickness gradually increases and finally occupies the entire pipe. The distance from the inlet to the point where the boundary layer merges and occupies the entire pipe is called hydrodynamic entry length $\left(L_{e}\right)$. Beyond this point the flow is assumed to be hydro-dynamically fully developed. The hydrodynamic entry length calculations are based on two different methods. In the first method it is assumed that the free-stream velocity at the centerline varies with the axial distance and a boundary layer is developed along the pipe. In this method integral momentum with boundary layer is adopted. In the second method the initial conditions are
Öz

Bu sayısal çalıșmada, en kesit șekillerinin ve yüzey pürüzlülüklerinin borulardaki hidrodinamik giriş uzunluğuna olan etkileri farklı Reynolds (Re) sayıları için incelenmiștir. Dairesel, kare ve eșkenar üçen kesitli borulardaki türbülanslı akışı analiz etmek için standart $k$ - $\varepsilon$ türbülans modeli kullanılmıștır. Analizler pürüzlü yüzeyli borulardaki giriș uzunluğunun pürüzsüz borulardakine göre daha kısa olduğunu göstermiştir. Ayrıca, yüzey pürüzlülüğünü artırmak borunun en kesit şeklinden bağımsız olarak giriş uzunluğunu kısaltmaktadır. Eşkenar üçgen kesitli boruların en uzun, dairesel kesitli boruların ise en kısa giriș uzunluğuna sahip oldukları görülmüștür. Re sayısı giriș uzunluğu üzerinde önemli etkilere sahiptir ve Re sayısı ne kadar büyürse giriş uzunluğunun da o kadar arttığı sonucuna varılmıştır.

Anahtar kelimeler: Hesaplamalı akışkanlar dinamiği, İç akışlar, Pürüzlülük, Türbülanslı akıșlar, Giriș uzunluğu

given by a uniform velocity distribution throughout the crosssection of the pipe. The method assumes that transient term can be treated like the convection term for steady developing flows. Transient velocity distribution is used to calculate the time to achieve steady state condition. From the calculated time and average velocity, the distance travelled by a fluid particle to reach the developed stage is found. This is the hydrodynamic entry length [3].

The estimation of $L_{e}$ is very important because some equations such as the Darcy-Weisbach equation for frictional head loss, often applies only to the hydro-dynamically fully developed flow portion of the pipe flow. Furthermore, measurement devices such as orifice plates, venture tubes, flow nozzles pitot tubes, hot-wire anemometers, etc, must be placed in the region where the flow is hydro-dynamically fully developed. Otherwise, improper installation of such devices leads to inaccurate readings and resulting wrong calculations. In the literature on fluid mechanics and heat transfer numerous studies and formulas about entry length have been reported so far. For instance, it was proposed that the entry length for turbulent flows in circular pipe can be taken as 50 times of pipe diameter, $D$ [2]. Another suggestion was stated as follow [4]:

$$
\left(\frac{L_{e}}{D}\right)_{\text {laminar }}=4.4 R e_{D}^{1 / 6}
$$

Where $R e_{D}$ is the Reynolds number based on pipe diameter (D). Some other formulas on the entry length in both laminar and turbulent flows are given in Equation (2-8) [1],[5]-[7]. 


$$
\begin{aligned}
\left(\frac{L_{e}}{D}\right)_{\text {laminar }} & =0.05 R e \\
\left(\frac{L_{e}}{D}\right)_{\text {turbulent }} & =1.359 \operatorname{Re}_{D}^{1 / 4} \\
\left(\frac{L_{e}}{D}\right)_{\text {laminar }} & =0.06 R e \\
\left(\frac{L_{e}}{D}\right)_{\text {turbulent }} & =4.4 R e^{1 / 6} \\
\left(\frac{L_{e}}{D}\right)_{\text {laminar }} & =0.065 R e \\
\left(\frac{L_{e}}{D}\right)_{\text {turbulent }} & =0.693 R e_{D}^{1 / 4} \\
\left(\frac{L_{e}}{D}\right)_{\text {laminar }} & =0.057 R e
\end{aligned}
$$

Although large number of formulas have been reported to calculate the entry length in circular cross-sectional pipes a few works have been done on non-circular pipes. The oldest expression on the subject was proposed as follows [8],[9]:

$$
x_{e}=\frac{x_{e}^{\prime}}{D}=\frac{0.6}{(0.035 R e+1)}+0.056 R e
$$

Where $x_{e}^{\prime}$ is the actual entry length. Equation (10) and Equation (11) were proposed for laminar flows in pipes and channels [10].

$$
\begin{aligned}
& \frac{L}{D}=\left[(0.619)^{1.6}+(0.0567 \mathrm{Re})^{1.6}\right]^{1.6} \\
& \frac{L}{D}=\left[(0.631)^{1.6}+(0.0442 \mathrm{Re})^{1.6}\right]^{1.6}
\end{aligned}
$$

Laminar flow in both circular and non-circular pipes were also investigated by Bahrami and Tamayol [11]. A study on the entry length in turbulent pipe flows presented that the centerline mean velocity is associated with ratio of boundary layer thickness and hydraulic diameter [12]. Velocity distribution in a two-dimensional (2D) model was showed by means of indirect turbulence model after the validation of the results with direct numerical simulation (DNS) of Navier-Stokes equation [13]. Axial velocity and skin friction coefficient distributions through a turbulent pipe flow were calculated [14] and pressure drop in circular and non-circular crosssectional pipes were analyzed for fully developed turbulent flows [15].

It was reported that the entry lengths in circular and noncircular conduits in laminar flows are not longer than that of the turbulent internal flows [16].

The entry length is not only important in fluid mechanics, but also in heat transfer where the counterpart of hydraulic entry length is the thermal entry length $\left(L_{t}\right)$. Thermal entry length is defined as the length from the pipe inlet to the point where the dimensionless temperature profile becomes invariant of the pipe length [17]. In turbulent flows, $L_{t}$ is relatively short due to intense turbulent transverse transport of energy. Up to now, several experimental and numerical studies have been reported for thermal entry length in literature for laminar, turbulent, smooth and rough surfaces [18]-[20]. It was reported that heat transfer coefficient that varies with the axial as well as radial distances depends on flow velocity, dimensions and surface nature [21]. Thermal entry length is characterized by Prandtl $(\mathrm{Pr})$ and Re numbers while hydrodynamic entry length depends on Re number. Both lengths may have the same values when $\operatorname{Pr} \approx 1$, or, for large $P r$, the thermal entry length may be very larger of the two [22].

Corresponding literature survey reveals that there are few studies dealt with the hydrodynamic entry length for circular and non-circular cross-sectional pipes. However, the effects of the roughness on the hydrodynamic entry length of pipes with various cross-sections have not been reported so far and this is the main motivation behind the present study. It should be noted here that the present study just focuses on the hydrodynamic entry length since thermal entry length is out of scope of the paper.

\section{Mathematical model and numerical method}

In the present study, effects of roughness on the entry length of pipes with various cross-sections have been investigated by considering three different cross-sections; circular, equilateral triangle and square as shown in Figure 1(b). For comparison, a common parameter called hydraulic diameter $\left(D_{h}\right)$ has been defined as given in Equation (12):

$$
D_{h}=\frac{4 \text { Area }}{\text { WetPerimeter }}
$$

Where area is the cross-sectional area of the pipes and the perimeter is the wetted surface. It should be noted here that for an appropriate comparison the hydraulic diameter of the circular, triangle and square cross-sectional pipes are fixed to $D_{h}=0.6 \mathrm{~m}$ while the length of the pipes are $50 \mathrm{~m}$. Simulations have been run for free-stream turbulence intensity (I) of 0.037 that was calculated as a function of Re number. As shown later, two more free-stream turbulence intensities have been used in the simulations to reveal its effects on the hydrodynamic entry length. Investigated geometries and corresponding values used in the simulations have been given in Table 1 . Water with density $\rho=997.561 \mathrm{~kg} / \mathrm{m}^{3}$ and dynamic viscosity $\mu=$ $8.887 \times 10^{-4}$ Pas has been used as working fluid that enters to the pipe from left-hand side and leaves it from the right side as shown in Figure 1(a). Therefore, left side of the pipe was defined as velocity inlet while the right one was specified as pressure outlet. All the remaining surfaces were assumed to be no-slip walls for the cases of smooth pipes and roughened surface pipes.

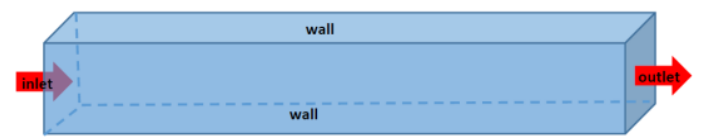

(a): Boundary conditions.

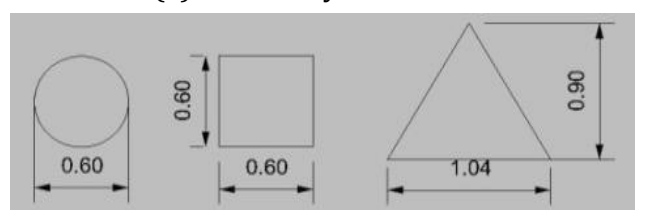

(b): Investigated cross-sections (dimensions are in m).

Figure 1: Boundary conditions and investigated cross sections. Initially, the walls were kept smooth and simulations were run for that case. Then, their surfaces were considered as rough wall with various heights as shown in Table 1. 
Table 1: Investigated geometries and corresponding values used in the simulations.

\begin{tabular}{cccc}
\hline & Circle & Square & Triangular \\
\hline $\mathrm{D}_{\mathrm{h}}(\mathrm{m})$ & 0.6 & 0.6 & 0.6 \\
& & & \\
& $1.20,2.39$, & $1.20,2.39$, & $1.20,2.39$, \\
$\mathrm{Re}_{\mathrm{Dh}}$ & $3.59,4.78$, & $3.59,4.78$, & $3.59,4.78$, \\
$\left(\mathrm{x} 10^{5}\right)$ & $5.98,7.17$ & $5.98,7.17$ & $5.98,7.17$ \\
& & & \\
& 0.0000 & 0.0000 & 0.0000 \\
$\varepsilon / \mathrm{D}_{\mathrm{h}}$ & 0.0167, & 0.0167, & 0.0167, \\
& 0.0333, & 0.0333, & 0.0333, \\
& 0.0500, & 0.0500, & 0.0500, \\
\hline
\end{tabular}

Pipe geometries have been split into several volumes called grid or mesh. The mesh structure applied to the pipes is given in Figure 2.

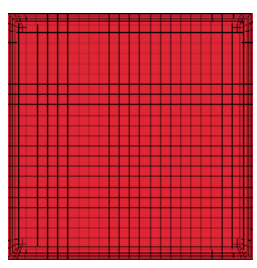

(a): Square.

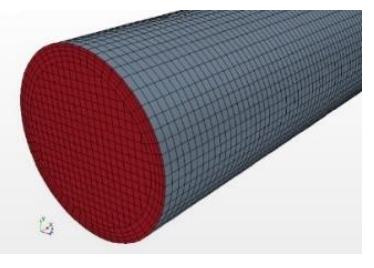

(b): Circular.
Figure 2: Mesh structure for different geometries.

Grid density has been increased towards the surfaces of the pipes to obtain the desired $\mathrm{y}^{+}$value as shown in Figure 3. The non-dimensional distance between the wall surfaces to the first grid point can be calculated by means of $\mathrm{y}^{+}$value. Figure 3 makes clear that the maximum magnitude of the $y^{+}$is less than 50 at the inlet. At the pipe surfaces it reduces to approximately 30 .

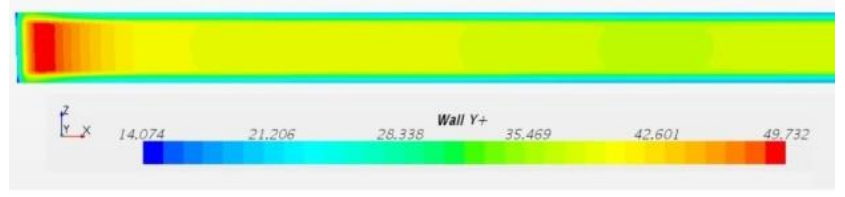

Figure 3: Wall $\mathrm{y}^{+}$distributions along the pipe.

Before proceeding into the analyses a grid independence study was performed for the same grid structure. Grids (meshes) are termed depending on their number of mesh elements such as; rough mesh (104664 elements), normal mesh (305388 elements), fine mesh (1421508 elements) and finally finer mesh (2010572 elements). Analyses have been performed with each mesh and their results were compared in terms of axial velocity distribution. Figure 4 shows the grid independence study performed for a square cross-sectional smooth pipe. Comparisons reveal that from the inlet to the point where axial velocity reaches its maximum almost all the meshes have the same velocity distribution. Although this is partially correct for the region where flow is fully develop, however, there are some minor discrepancies between the rough and finer meshes after decreasing of the axial velocities and getting to a plateau. From $x / D_{h}=60$ to the pipe exit all meshes have the same velocity magnitude. In the recovering region the fine mesh is closest to the finer one and therefore, other meshes have been eliminated. Considering the available computational resources all the remaining simulations have been carried out with the fine mesh.

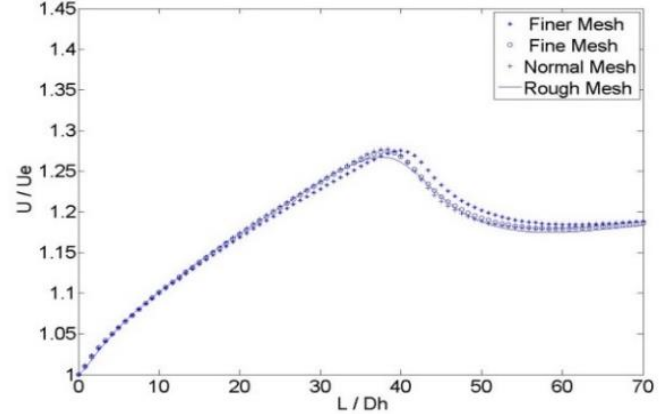

Figure 4: Mesh independence study.

The steady - incompressible continuity (Equation (13)) and momentum equations (Equation (14)) are given as follows.

$$
\begin{gathered}
\frac{\partial U_{i}}{\partial x_{j}}=0 \\
U_{i} \frac{\partial U_{j}}{\partial x_{i}}=-\frac{1}{\rho} \frac{\partial p}{\partial x_{j}}+\frac{\partial}{\partial x_{i}}\left(v \frac{\partial U_{j}}{\partial x_{i}}-\overline{u_{\imath} u_{\jmath}}\right)
\end{gathered}
$$

Where $U$ stands for the velocity components, $p, \rho$ and $v$ represents the pressure, density and kinematic viscosity of the fluid [1]. When a decomposition is applied to the flow variables (velocity components and pressure) these variables must be rewritten in terms of mean and fluctuating components. Reynolds stresses in the end of the momentum equations need to be modeled to get a solution. Such models are known turbulence models. Although several turbulence models are available in the literature, standard $k-\varepsilon$ (SKE) turbulence model has been adopted in the present study since it was proved that SKE turbulence model can be used for duct flows [23],[24]. The governing equations for SKE turbulence model have been given for turbulence kinetic energy, $k$ (Equation (15)) and its dissipation rate, $\varepsilon$ (Equation (16)) as given below [25]:

$$
\begin{gathered}
\frac{\partial(\rho k)}{\partial t}+\operatorname{div}(\rho \mathrm{kU})=\operatorname{div}\left(\frac{\mu_{t}}{\sigma_{k}} \operatorname{gradk}\right)+2 \mu_{t} S_{i j} S_{i j}-\rho \varepsilon \\
\frac{\partial(\rho \varepsilon)}{\partial t}+\operatorname{div}(\rho \varepsilon \mathrm{U})=\operatorname{div}\left(\frac{\mu_{t}}{\sigma_{\varepsilon}} \operatorname{grad} \varepsilon\right)+ \\
C_{1 \varepsilon} \frac{\varepsilon}{k} 2 \mu_{t} S_{i j} S_{i j}-C_{2 \varepsilon} \rho \frac{\varepsilon^{2}}{k}
\end{gathered}
$$

Where the first terms in the above equations represent the time rate of change of $k$ or $\varepsilon$ and transport of $k$ or $\varepsilon$ by convection. The other terms in the right hand side of the equations are for transport of $k$ or $\varepsilon$ by diffusion, rate of production of $k$ or $\varepsilon$ and finally rate of destruction of $k$ or $\varepsilon$, respectively. Eddy viscosity, $\mu_{t}$ is defined as given in Equation (17):

$$
\mu_{t}=\rho C_{\mu} \frac{k^{2}}{\varepsilon}
$$

The magnitude of the dimensionless constants presented in Equation (14) - Equation (17) are given in Table 2.

Table 2: Empirical constants employed in equations.

\begin{tabular}{ccccc}
\hline$C_{\mu}$ & $\sigma_{k}$ & $\sigma_{\varepsilon}$ & $C_{1 \varepsilon}$ & $C_{2 \varepsilon}$ \\
\hline 0.09 & 1.00 & 1.30 & 1.44 & 1.92 \\
\hline
\end{tabular}

Pressure field is solved by SIMPLE algorithm which is based on pressure-velocity coupling. SIMPLE is a commonly used algorithm for calculating pressure and velocity fields in an iterative manner. All the governing equations are discretized using a cell based finite volume method and the advection 
terms are discretized with a first-order upwind interpolation scheme. In the present study, the numerical results were obtained by solving the above equations iteratively. Each computation took approximately 1000 1500 iterations were continued until residuals were less than $10^{-3}$ for all cases.

\section{Results}

Validation of the present simulations have been done by comparing them with the data of Anselmet et al. [12]. From Figure 5 it is seen that there are a perfect agreement between two studies from the inlet of the pipe to $x / D h=30$ where it is defined as hydro-dynamically developing region. In the hydrodynamically developing region the axial velocity accelerates due to the thickening of the velocity boundary layer regarding the shape of the cross-section of the pipe [12]. Although the maximum velocity reported by Anselmet et al. [12] decreases after $x / D_{h}=30$, velocity obtained from the present study increases approximately $4 \%$ until $x / D_{h}=38$. Then it decreases and follows the experimental data from $x / D_{h}=50$ to the outlet of the pipe. The region where axial velocities do not change any more is the hydro-dynamically developed flow region. A discrepancy between two results is seen in the region that covers $30<x / D_{h}<50$.

The region that starts from the station where the axial velocity makes a peak and to the station that the velocity stabilizes is the region where the flow is recovering. It has been thought that although it works well in the other regions, the turbulence model preferred in the present study is incapable to calculate the velocity distribution correctly in that complex region. It is seen that except that region the present study is agreed well with Anselmet et al [12] and Yuksel [2].

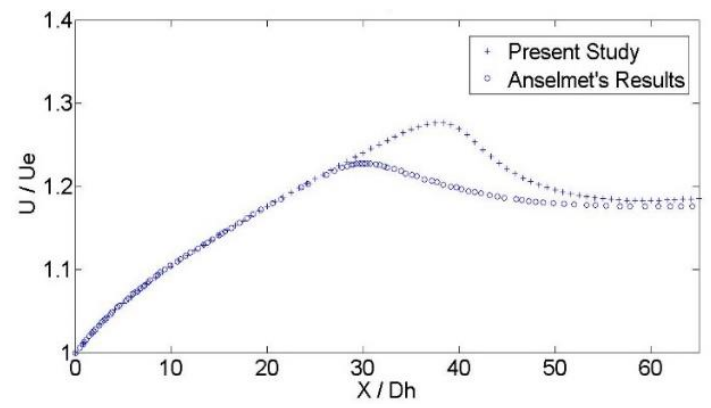

Figure 5: Axial velocity distributions of the present study and Anselmet et al.[12] at $R e=1.2 \times 10^{5}$.

Development of the flow has been checked by comparing the velocity distributions at $x / D_{h}=25$ and $x / D_{h}=58.33$. Figure 6 reveals that the flow has not become fully developed yet at $x / D_{h}=25$ since the velocity profile is completely flat at the region covers $-0.2<y / D_{h}<0.2$.

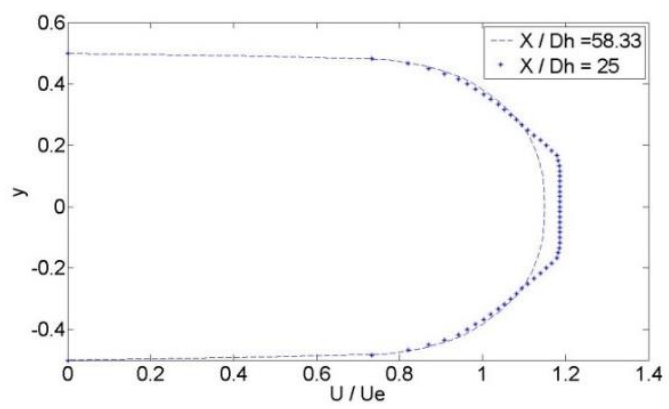

Figure 6: Axial velocity distributions at various stations in the square cross-sectional pipe.
Validation of the present numerical study is also performed by comparing the results with the solution of $1 / n$ power law velocity profile:

$$
\frac{u}{u_{e}}=\left(\frac{y}{\delta}\right)^{1 / n}
$$

Where $u, u_{e}, y, \delta$ and $\mathrm{n}$ stands for $\mathrm{x}$-velocity at any location, inlet velocity in $\mathrm{x}$-direction, boundary layer thickness and constant, respectively. Theoretical velocity distributions are presented for two different $\mathrm{n}$ values; $n=6$ and $n=7$ (Figure 7). It is demonstrated that the theoretical and computational results are in good agreement specifically after $y / \delta=0.5$. Despite the fact that some differences are occurred from the inlet to $y / \delta=$ 0.5 , both numerical and theoretical velocities have the same distribution in the remaining parts of the boundary layer.

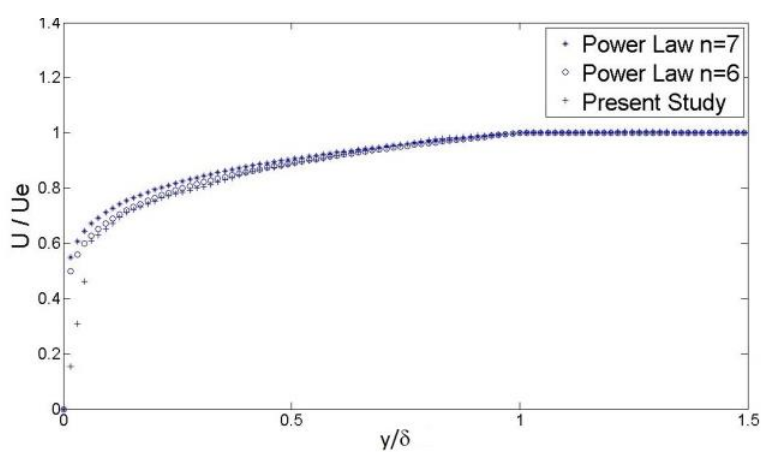

Figure 7: Comparison of the axial velocity distributions in the circular cross-sectional pipe.

Before proceeding into the analyses in more detail the effects of turbulence intensity $(I)$ on the entrance length have been investigated. As Figure 8 implies the hydrodynamic entry length is barely affected by the increase of the freestream inlet turbulence intensity. This is fairly consistent with the results reported for a helically coiled pipe [26].

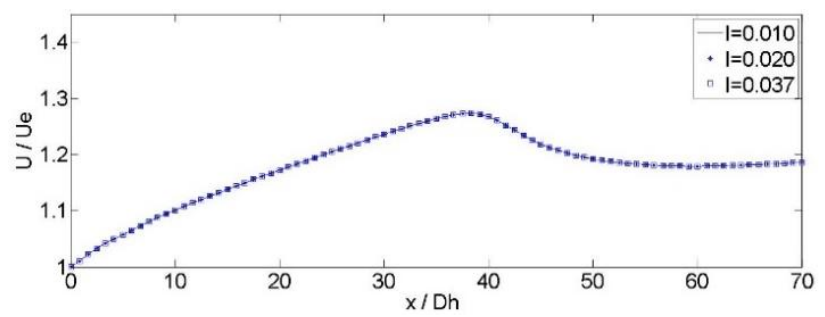

Figure 8: Effects of turbulence intensity (I) on the entry length.

Effects of roughness in a square cross-sectional pipe are given in Figure 9 where the change of axial velocities is demonstrated for roughness of $\varepsilon / D_{h}=0.0167,0.0333,0.0500$ and 0.0667 . At $R e=1.19 \times 10^{5}$ it is seen that there is a direct proportion between the roughness height and maximum velocity at the centerline of the square pipe. When the square pipe surface is assigned to be roughed of $\varepsilon / D_{h}=0.0167$ velocity becomes higher than that of the smooth pipe along all the pipe. When the roughness of the pipe surface increases the velocities at any location along the pipe and maximum velocity values increase as well. Another result that is consistent with the literature is that increasing the roughness shortens the entry length since the flow can able to be fully developed at earlier positions. 


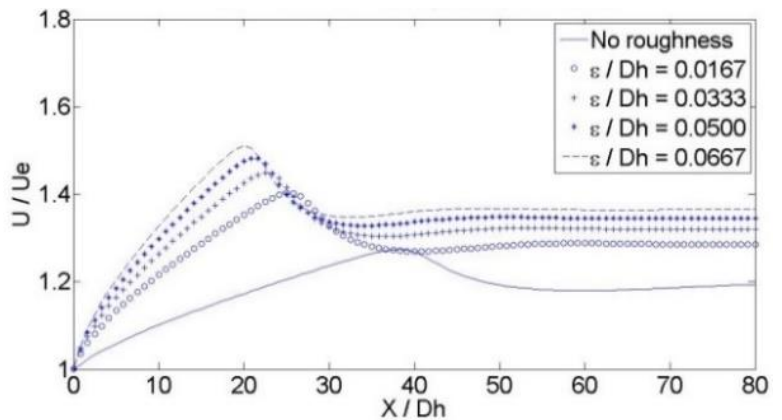

Figure 9: Effect of roughness on the axial velocity of a square cross-sectional pipe $\left(R e=1.19 \times 10^{5}\right)$.

In Figure 10 effects of roughness in a circular cross-sectional pipe are depicted. It is clear that the correlation between the roughness height and entry length is almost the same for square cross-sectional pipe. However, the magnitudes of the maximum velocities at any roughness in the circular crosssectional pipe are lower than the maximum velocities occur in square cross-sectional one and the flow becomes fully developed in a shorter distance when the pipe is circular crosssectional. Velocity distributions reveal that the higher surface roughness leads forming the flow to be fully developed in advance regardless of the cross-section of the pipe.

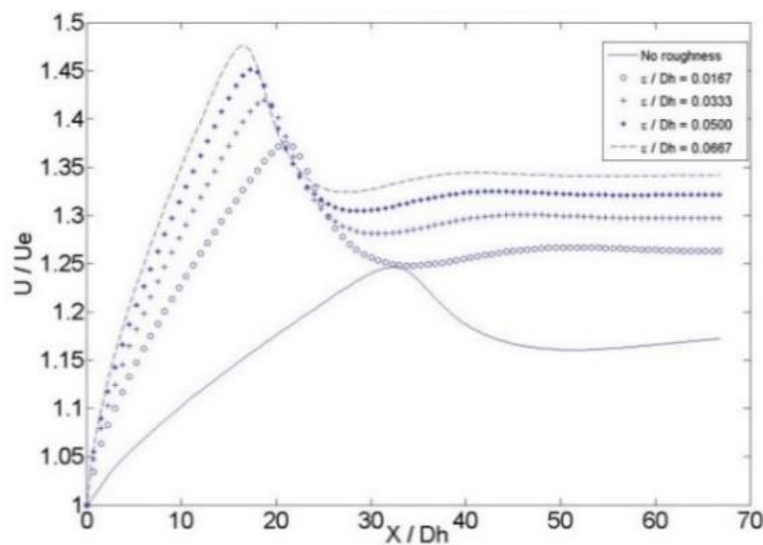

Figure 10: Effects of roughness on the axial velocity distribution in the circular cross-sectional pipe $(R e=1.19 \times$ $\left.10^{5}\right)$.

Velocity distributions demonstrated in Figure 11 for smooth and roughened equilateral triangle cross-sectional pipes display that the entry length in equilateral triangle pipe is quite close to the entry length in square cross-sectional pipe and longer than that of the circular cross-sectional pipes as shown later.

Effects of inlet velocities on the entry lengths in smooth pipes with different cross sections are presented in Figure 12. Figure 12a reveals that the longest entry length is formed in the triangle cross-sectional pipe while the shortest is seen at the circular cross-sectional one at $R e=1.15 \times 10^{5}$. When $\mathrm{Re}$ number increases the entry lengths for all geometries increase. The maximum velocity occurs in the equilateral triangle while the lowest velocity magnitude is occurred in circular cross-sectional pipe regardless of the Re number. Figure 12 deduces that when Re number increases the magnitude of the maximum velocity decreases a bit no matter the cross-section of the pipes.

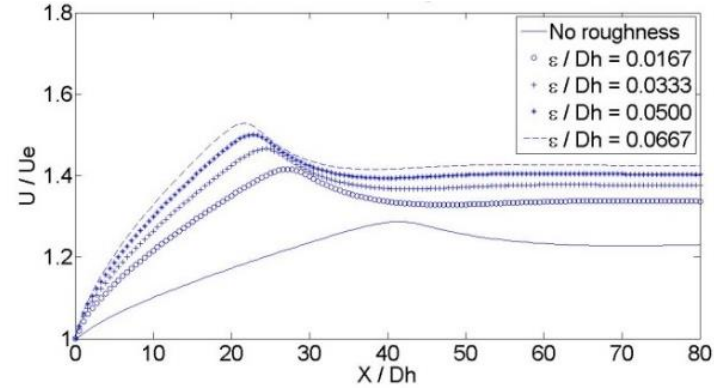

Figure 11: Effect of roughness on the axial velocity distribution in the equilateral triangle cross-sectional pipe $(R e=1.19 \times$ $10^{5}$ ).

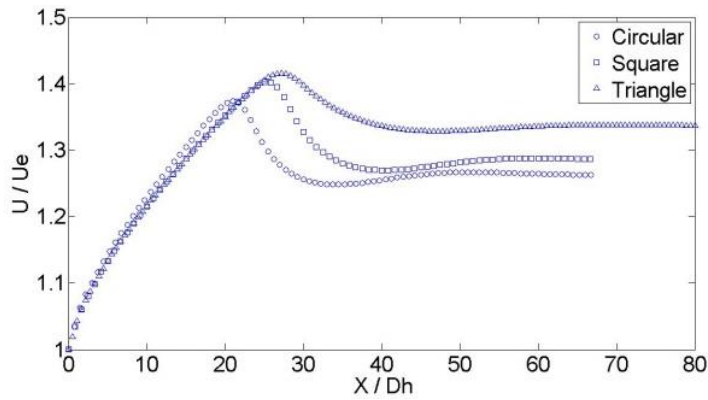

(a): $R e=1.15 \times 10^{5}$.

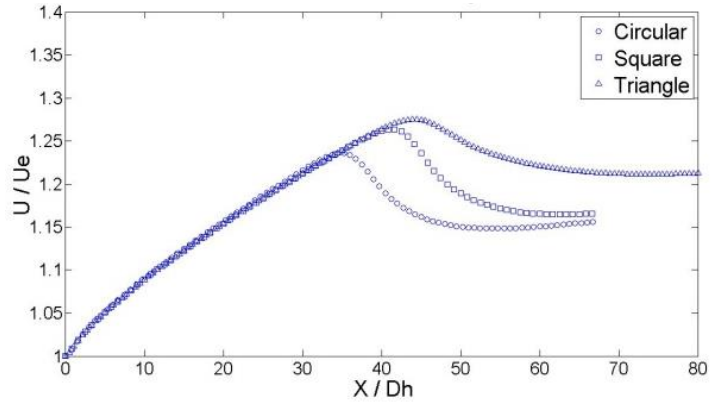

(b): $R e=2.39 \times 10^{5}$.

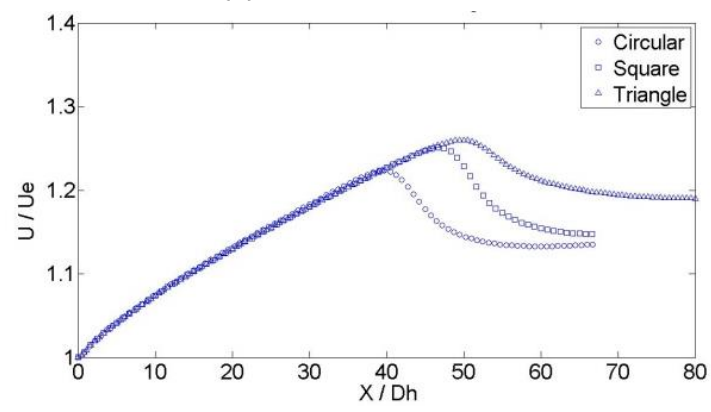

(c): $R e=7.17 \times 10^{5}$.

Figure 12: Axial velocity distribution in smooth pipes with various cross sections at different Re numbers.

Change of entry lengths with Re number are given in Figure 13 for vast range of Re numbers when the walls of the pipes are smooth. These lengths were measured where the fluctuation of axial velocities were less than \%1.7. Although it is known that the thermal and hydrodynamic entry lengths are shorter in turbulent flows than that of the laminar flows, the hydrodynamic entry length may change with Re numbers because at high velocities the boundary layer on the pipe 
surface will be suppressed by the flow that delays the merging of the boundary layer and extends the entry length. It is seen that entry lengths increase with Re number as aforementioned. At partially low Re numbers the lengths of the hydrodynamically developing regions are very close to each other`s. However, as Re number increases the length of the hydrodynamically developing region increases and the gaps between the magnitudes of the entry lengths increase several fold.

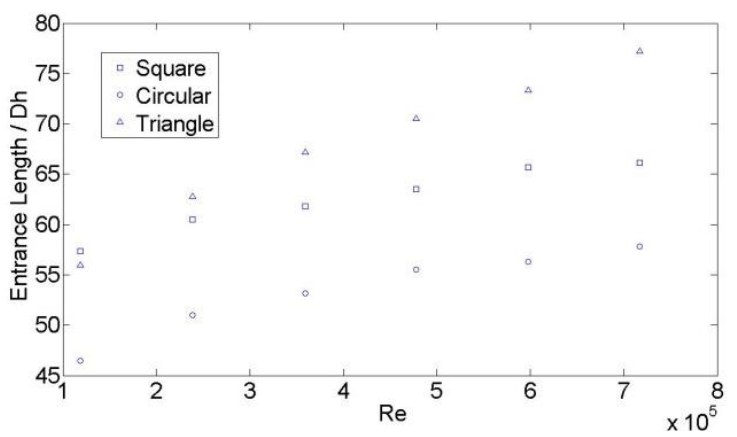

Figure 13: Entry length at various Re numbers in square, circular and triangle cross-sectional pipes.

\section{Conclusion}

In the present numerical study, effects of surface roughness and geometrical shape of cross-section of the pipes on hydrodynamic entry length are investigated at various $\mathrm{Re}$ numbers. Series of simulations reveal that when the pipe surfaces are kept smooth the circular cross-sectional pipe has the shortest hydrodynamic entry length while equilateral triangle square cross-sectional pipe has the longest. When the surfaces are rough the shortest and longest entry lengths are occurred in equilateral triangle and circular cross-sectional pipes, respectively. It is deduced that Re number has a great effect on the entry length regardless of the surface roughness and type of the cross-section of the pipe.

\section{References}

[1] Cengel YA, Cimbala JM. Fluid Mechanics: Fundamentals and Application. $1^{\text {st }}$ ed. McGraw-Hill, 2006.

[2] Yuksel Y. Advanced Fluid Mechanics. Istanbul, Beta, 2014.

[3] Sahu M, Singh P, Mahapatra SS, Khatua KK. "Prediction of entrance length for low reynolds number flow in pipe using neuro-fuzzy inference system". Expert Systems with Applications, 39(4), 4545-4557, 2012.

[4] White FM. Fluid Mechanics. $8^{\text {th }}$ ed. New York, USA, McGrew Hill, 2015.

[5] Munson BR, Okiishi TH, Huebsch WW, Rothmayer AP. Fundamentals of Fluid Mechanics. $7^{\text {th }}$ ed. John Wiley \& Sons, 2013

[6] Nakayama Y, Boucher RF. Introduction to Fluid Mechanics. Butterworth-Heinemann, 1998.

[7] Massey B, Ward-Smith J. Mechanics of Fluids. $8^{\text {th }}$ ed. Taylor and Francis, 2006

[8] Friedmann M, Gills J, Liron N. "Laminar flow in pipe at low and moderate reynolds numbers". Applied Scientific Research, 19(1), 426-438, 1968.

[9] Chen RY. "Flow in the entrance region at low Reynolds numbers". Journal of Fluid Engineering, 95(1), 153-158, 1973.
[10] Durst F, Ray S, Unsal B, Bayoumi OA. "The development lengths of laminar pipe and channel flows". Journal of Fluids Engineering, 127(6), 1154-1160, 2005.

[11] Bahrami M, Tamayol A. "Laminar flow in microchannels with noncircular cross section". Journal of Fluids Engineering, 132(11), 111201-111201, 2010.

[12] Anselmet F, Ternat F, Amielh M, Boiron 0, Boyer P, Pietri L. "Axial development of the mean flow in the entrance region of turbulent pipe and duct flows". Comptes Rendus Mécanique, 337(8), 573-584, 2009.

[13] Di Nucci C, Spena AR. "Mean velocity profiles of twodimensional fully developed turbulent flows". Comptes Rendus Mécanique, 340(9), 629-640, 2012.

[14] Bhandari D, Singh S. "Analysis of fully developed turbulent flow in a pipe using computational fluid Dynamics". International Journal of Engineering Research and Technology, 1(5), 1-8, 2012.

[15] Duan Z, Yovanovich MM, Muzychka YS. "Pressure drop for fully developed turbulent flow in circular and noncircular ducts". Journal of Fluids Engineering, 134(66), 061201061210, 2012.

[16] Tongpun PT, Bumrungthaichaichan E, Wattananusorn S. "Investigation of entrance length in circular and noncircular conduits by computational fluid dynamics simulation". Songklanakarin Journal of Science and Technology, 36(4), 471-475, 2014.

[17] Shah RK, London AL. "Flow Friction in Straight and Curved Ducts-A Summary of Analytical Solutions". Technical Department of Mechanical Engineering, Stanford University, Stanford, California, USA, Report, 75, 1971.

[18] Lee PS, Garimella SV. "Thermally Developing Flow and Heat Transfer on Rectangular Microchannels of Different Aspect Ratios". CTRC Research Publications. Paper 23, 2006.

[19] Hayes RE, Donoso-Bravo A, Mmbaga JP. "Entry length effects for momentum, heat and mass transfer in circular ducts with laminar flow". Canadian Journal of Chemical Engineering, 93, 863-869, 2015.

[20] Kandlikar SG, Joshi S, Tian S. "Effect of surface roughness on heat transfer and fluid flow characteristics at low reynolds numbers in small diameter tubes". Heat Transfer Engineering, 24(3), 4-16, 2003.

[21] Hasan 0. "Heat transfer analysis in thermal entrance region under turbulent flow conditions". Asia-Pacific Journal of Chemical Engineering, 8(4), 579-592, 2013.

[22] Hayes RE, Donoso-Bravo A, Mmbaga JP. "Entry length effects for momentum, heat and mass transfer in circular ducts with laminar flow". The Canadian Journal of Chemical Engineering, 93(5), 863-869, 2015.

[23] Wang LB, Wang QW, He YL, Tao WQ. "Experimental and numerical study of developing turbulent flow and heat transfer in convergent/divergent square duct". Heat and Mass Transfer, 38(4), 399-408, 2002.

[24] Alberts-Chico X, Perez-Segarra CD, Oliva A, Bredberg J. "Analysis of wall-function approaches using two-equation turbulence models". International Journal of Heat and Mass Transfer, 51(19-20), 4940-4957, 2008.

[25] Versteeg HK, Malalasekera W. An Introduction to Computational Fluid Dynamics: The Finite Volume Method. 2nd ed. Pearson Prentice Hall, 2007.

[26] Lin CX, Ebadian MA. "The effects of inlet turbulence on the development of fluid flow and heat transfer in a helically coiled pipe". International Journal of Heat and Mass Transfer, 42(4), 739-751, 1999. 